\title{
De ontwikkeling van een instrument om het functioneren van begeleiders van de klinische onderwijsgroep te meten
}

\author{
I. Oosterhof, W.S. de Grave, D.H.J.M. Dolmans, N.C. Schaper, C.P.M. van der Vleuten
}

\section{Samenvatting}

Inleiding: Het doel van de negen bijeenkomsten van de klinische onderwijsgroepen (KOW) in het vierde jaar van het huidige Maastrichtse geneeskundecurriculum is het bevorderen van integratie van biomedische en klinische kennis en het hypothesegestuurd afnemen van de anamnese. Tijdens de bijeenkomst wordt bij een patiënt de anamnese afgenomen en dit wordt nabesproken. De KOW-begeleider is een clinicus die bekend is met de patiëntenproblematiek. In dit onderzoek is een vragenlijst ontwikkeld om het functioneren van de $\mathrm{KOW}$ begeleiders te meten.

Methode: Er is een vragenlijst ontwikkeld bestaande uit 35 stellingen over het gedrag van de begeleider (vijfpunts Likertschaal). In het academisch jaar 2000-2001 hebben 190 studenten direct na afloop van elke KOW-bijeenkomst in totaal 1150 vragenlijsten ingevuld ter beoordeling van 51 begeleiders. Er is een factoranalyse uitgevoerd, de interne consistentie van de vragenlijst is berekend en met behulp van one-way Anova is gekeken naar verschillen tussen de begeleiders.

Resultaten: Uit de factoranalyse kwamen zeven dimensies naar voren: elaboratie, reflectieop-actie, encapsulatie, vervolgen van het consult, reflectie-in-actie, gebruik van de patiënt als leermiddel en zelfsturing. De interne consistentie bleek over het algemeen hoog te zijn. De vergelijking van de begeleiders gaf significante verschillen te zien op een aantal dimensies.

Conclusie: De vragenlijst is intern consistent en valide gebleken. De begeleiders die van de studenten de beste beoordeling krijgen, worden gekenmerkt door hoge scores op de dimensies elaboratie en encapsulatie. De resultaten van dit onderzoek kunnen behulpzaam zijn bij training van en het geven van feedback aan begeleiders. (Oosterhof I, Grave WS de, Dolmans DHJM, Schaper NC, Vleuten CPM van der. De ontwikkeling van een instrument om het functioneren van begeleiders van de klinische onderwijsgroep te meten. Tijdschrift voor Medisch Onderwijs 2002;21(3): 122-130.)

\section{Inleiding}

In Maastricht worden in het vierde jaar van de studie geneeskunde klinische onderwijsgroepen (KOW) georganiseerd. Het doel van de groepsbijeenkomsten is het vergemakkelijken van de overgang tussen de theorie in de eerste vier jaar van de studie en de praktijk tijdens de co-assistentschappen in de laatste twee jaar. Uit onderzoek is namelijk gebleken dat studenten moeite hebben de kennis die ze opdoen in de eerste jaren van hun opleiding toe te passen in contacten met echte patiënten tijdens de co-assistentschappen. Dit geldt ook voor een probleemgestuurd curriculum, waarin studenten al vanaf jaar één in aanraking komen met (schriftelijke) patiëntencasuïstiek. $^{1}$

De groepen bestaan uit tien studenten. De samenstelling blijft het hele jaar hetzelfde en per groep zijn er negen bijeenkomsten van negentig minuten, waarvan zeven met patiënten: twee bijeenkomsten bij de Capaciteitsgroep Neurologie, twee bij de Capaciteitsgroep Chirurgie en drie 
bij de Capaciteitsgroep Interne Geneeskunde. Elke bijeenkomst wordt begeleid door een klinisch docent die inhoudelijk goed op de hoogte is van de patiëntenproblematiek. De begeleider wisselt per bijeenkomst, afhankelijk van de capaciteitsgroep en de thematiek die wordt behandeld. De bijeenkomsten zijn niet blokgebonden. Tijdens de eerste 45 minuten van de KOW-bijeenkomst is er een patiënt aanwezig. De studenten nemen bij de patiënt de anamnese af en in de tweede helft van de bijeenkomst worden inhoud en vorm van de anamnese nabesproken. De KOW-bijeenkomsten vinden over het algemeen plaats in een aparte ruimte in het ziekenhuis, niet aan het bed van de patiënt. De patiënten gaan dus naar de studenten toe. Zowel chronische als acute patiënten worden voor deze vorm van onderwijs benaderd. Soms zijn dit patiënten op een afdeling in het ziekenhuis, maar regelmatig komen patiënten speciaal voor de KOW-bijeenkomsten naar het ziekenhuis. $^{2}$

De nadruk in de KOW-bijeenkomsten ligt op het hypothesegestuurd afnemen van de anamnese bij een echte patiënt en de nabespreking hiervan. Het is de bedoeling dat hierdoor onder andere elaboratie en encapsulatie van kennis evenals reflectie op het handelen gestimuleerd worden teneinde de integratie van biomedische en klinische kennis te bevorderen. We gaan nu eerst kort in op de begrippen elaboratie, encapsulatie en reflectie.

Een groep studenten die een nieuw probleem, bijvoorbeeld een patiëntencasus, krijgt aangeboden, zoekt eerst verklaringen voor de problematiek op grond van reeds aanwezige kennis. Dit wordt elaboratie genoemd. Pas daarna wordt nieuwe voor het probleem relevante kennis aangeboden. Elaboratie leidt tot activatie, bewustwording en organisatie van kennis, waardoor relaties kunnen worden gelegd tussen wat iemand al weet en nieuwe klinische informatie die wordt aangeboden. ${ }^{3}$ Kortom, elaboratie bevordert het leren van nieuwe probleemrelevante informatie. 5 In de KOW-bijeenkomsten vindt elaboratie vooral plaats tijdens het afnemen van de anamnese.

Bij encapsulatie gaat het ook om de organisatie van kennis. ${ }^{6}$ Encapsulatie wordt door Schmidt en Boshuizen gedefinieerd als: "The subsumption or packaging of 'lower level' detailed concepts and their interrelations in an associative net, under a smaller number of 'higher level' concepts with the same explanatory power."7 Medische studenten hebben in de eerste jaren van hun studie al grote netwerken van biomedische kennis opgebouwd. Onder invloed van praktijkervaringen, zoals het diagnosticeren en behandelen van patiënten, zoals bijvoorbeeld in de KOW-bijeenkomsten, wordt deze biomedische kennis geïntegreerd in klinische kennis. Netwerken van gedetailleerde biomedische concepten worden weer ondergebracht onder een klein aantal compactere klinische concepten. Dit proces wordt encapsulatie genoemd. ${ }^{1} 489$

Reflectie is het instrument waarmee ervaringen vertaald worden in kennis, die in andere situaties gebruikt kan worden. ${ }^{10}$ Reflectie kan onderverdeeld worden in reflectie-in-actie en reflectie-op-actie. Reflectie-in-actie vindt plaats tijdens een handeling. Bij reflectie-op-actie wordt een voorafgaande handeling geanalyseerd en kritisch geëvalueerd om het toekomstig handelen te verbeteren. ${ }^{10}$ Door middel van reflectie-op-actie wordt studenten tevens de mogelijkheid geboden om hardop te denken, om te zeggen wat er in hun hoofd omgaat, zonder dat de patiënt (in een KOW-bijeenkomst) daarbij aanwezig is. ${ }^{11}$

Het belang dat gehecht wordt aan elaboratie, encapsulatie en reflectie in de KOW-groepen komt voort uit de opvatting 
dat studenten hierdoor een coherent kennisnetwerk ontwikkelen dat flexibiliteit in het gebruik van deze kennis bevordert. Het contact met echte patiënten zorgt er voor dat studenten de relevantie zien van wat zij leren, waardoor hun motivatie versterkt zal worden. ${ }^{12}$

De begeleiders van de KOW-bijeenkomsten zijn allen clinici. Zij dienen een speciale workshop te volgen voordat ze KOW-begeleider worden. In deze workshop worden ze ingelicht over de uitgangspunten en de procedure van de KOW en over de rol van begeleider. De begeleider stimuleert het leerproces tijdens het contact met de patiënt en tijdens de nabespreking van de anamnese. Alle begeleiders hebben een PGO-cursus gevolgd en zijn tutor of ze hebben in het verleden tutorschappen vervuld. Dit betekent dat alle KOW-begeleiders ervaring hebben met het stimuleren van elaboratie, zelfsturing, reflectie en het groepsproces.

Tot nu toe is er weinig onderzoek gedaan naar het functioneren van de KOW-begeleiders. Uit de gegevens van de programma-evaluatie van de afgelopen jaren blijkt dat KOW-begeleiders over het algemeen hoog worden gewaardeerd. Uit focusgroeponderzoek is gebleken dat studenten vinden dat een goede KOW-begeleider enthousiast is en het groepsproces op een kritische manier stuurt. ${ }^{2}$

Het doel van dit onderzoek is een vragenlijst te ontwikkelen om te meten in welke mate KOW-begeleiders studenten stimuleren om te elaboreren, te encapsuleren en te reflecteren. Hiertoe zijn de volgende vragen geformuleerd: Is de ontwikkelde vragenlijst intern consistent en valide? Zijn er verschillen in het gedrag van de begeleiders in de perceptie van studenten? Zijn er in de perceptie van de studenten verschillen tussen de begeleiders van de verschillende capaciteitsgroepen die de KOW-bijeenkomsten verzorgen?

\section{Methode}

\section{Proefpersonen}

In totaal zijn 51 begeleiders verschillende malen door minimaal vijf verschillende studenten beoordeeld. Elf begeleiders zijn afkomstig van de Capaciteitsgroep Neurologie, twintig van de Capaciteitsgroep Chirurgie en twintig van de Capaciteitsgroep Interne Geneeskunde.

\section{Instrument}

Er is een vragenlijst ontwikkeld aan de hand van bestaande vragenlijsten, de doelstellingen van de KOW en relevante literatuur over verschillende dimensies die van belang zijn bij de begeleiding van de KOW-bijeenkomsten, te weten: elaboratie, encapsulatie, gebruik van de patiënt als leermiddel, reflectie-in-actie, reflectieop-actie, zelfsturing en vervolgen van het consult. Voorbeelden van items uit de vragenlijst behorende bij de zeven dimensies, zijn te vinden in figuur 1.

De totale vragenlijst bestaat uit 35 stellingen over het gedrag van de begeleider. Studenten werd gevraagd om hun oordeel te geven op een vijfpunts Likertschaal ( 1 = geheel oneens, 5 = geheel eens $)$. De vragenlijsten werden direct na afloop van iedere bijeenkomst ingevuld. De studenten vulden op dat moment tevens de formulieren in van de reguliere programma-evaluatie. Hierin kunnen studenten onder andere een cijfer van één tot tien geven voor het functioneren van de begeleider. Dit cijfer is in dit onderzoek gebruikt als algemeen oordeel over de begeleider.

\section{Procedure}

Het onderzoek is gedurende het academisch jaar 2000-2001 uitgevoerd in het vierde jaar van het Maastrichtse geneeskundecurriculum. Van de 194 vierdejaarsstudenten hebben zich 190 ingeschreven voor de KOW. Deze 190 studenten hebben 
Figuur 1. Items uit de vragenlijst behorende bij de zeven dimensies.

\begin{tabular}{|c|c|}
\hline Dimensie & Item \\
\hline Elaboratie & $\begin{array}{l}\text { Stimuleert tot het stellen van relevante vragen (niet het standaard- } \\
\text { rijtje van de tractusanamnese afgaan). }\end{array}$ \\
\hline Reflectie-op-actie & $\begin{array}{l}\text { Stimuleert tot het bewust worden van de beperkingen in het } \\
\text { afnemen van de anamnese. }\end{array}$ \\
\hline Encapsulatie & $\begin{array}{l}\text { Stimuleert tot het leggen van relaties tussen pathofysiologie en de } \\
\text { verschillende klachten van de patiënt. }\end{array}$ \\
\hline Vervolgen van het consult & $\begin{array}{l}\text { Vraagt naar de functie van mogelijk aanvullend diagnostisch } \\
\text { onderzoek. }\end{array}$ \\
\hline Reflectie-in-actie & Stimuleert een student om tussentijds samen te vatten. \\
\hline Gebruik van de patiënt als leermiddel & $\begin{array}{l}\text { Stimuleert (zo nodig) de patiënt om meer te vertellen of te } \\
\text { verduidelijken. }\end{array}$ \\
\hline Zelfsturing & $\begin{array}{l}\text { Geeft de studenten voldoende ruimte om zelf de anamnese af te } \\
\text { nemen. }\end{array}$ \\
\hline
\end{tabular}

allen meegewerkt aan het onderzoek. Door deze 190 studenten is 1206 maal deelgenomen aan de KOW. In totaal zijn 1150 vragenlijsten ingevuld. Uiteindelijk bleken 1083 vragenlijsten bruikbaar voor verdere analyse. De bruikbare respons bedroeg dus $90 \%$. Het aantal vragenlijsten dat per bijeenkomst is ingevuld, bedroeg minimaal vijf en maximaal elf. In principe bestaat een groep uit tien studenten, maar doordat een enkele keer een student de KOW op een ander tijdstip gevolgd heeft, is er een deelname van maximaal elf studenten per groep. Voor het invullen van de vragenlijsten hebben de studenten een vergoeding ontvangen.

\section{Analyses}

Ter validatie van de vragenlijst is op studentniveau een exploratieve factoranalyse uitgevoerd om na te gaan welke dimensies aan de vragenlijst ten grondslag liggen. Per dimensie is de interne consistentie van de vragenlijst op studentniveau berekend. De data zijn verder geanalyseerd op begeleidersniveau.

Het gemiddelde cijfer uit de reguliere onderwijsevaluatie voor het functioneren van de 51 begeleiders was 7.70 (stan- daarddeviatie .6). Om de gegevens beter inzichtelijk te maken zijn de begeleiders op basis van het algemene oordeel (gemiddelde cijfer functioneren van een begeleider) ingedeeld in tertielen. Dit leverde de volgende groepen van zeventien begeleiders op: de relatief goed functionerende begeleiders (scores 8.00-8.60), de relatief gemiddeld functionerende begeleiders (scores 7.51-7.99) en de relatief matig functionerende begeleiders (scores 5.50-7.50). Indien de groepen op basis van absolute normen ingedeeld zouden zijn - bijvoorbeeld $<6.00,6.00-7.00$, $>7.00$-, zouden zij wat betreft grootte niet vergelijkbaar zijn. Daarom is gekozen voor tertielen. Met behulp van one-way ANOVA is onderzocht of de drie groepen begeleiders verschilden op dimensie- en op itemniveau. Met behulp van deze methode is ook gekeken naar verschillen op dimensieniveau tussen de begeleiders afkomstig van de drie capaciteitsgroepen.

\section{Resultaten}

Uit de exploratieve factoranalyse kwamen zeven dimensies naar voren: elaboratie, reflectie-op-actie, encapsulatie, vervolgen van het consult, reflectie-in-actie, gebruik 
Tabel 1. Per dimensie het aantal items, \% verklaarde variantie, score (standaarddeviatie) en interne consistentie $(\alpha)$.

\begin{tabular}{lllll}
\hline Dimensie & Aantal items & $\begin{array}{l}\text { Verklaarde } \\
\text { variantie }\end{array}$ & $\begin{array}{l}\text { Score }(\mathbf{s d}) \\
(\mathbf{n}=51)\end{array}$ & $\begin{array}{l}\alpha \\
(\mathbf{n}=1083)\end{array}$ \\
\hline Elaboratie & 7 & 28.7 & $4.0(.5)$ & .9 \\
Reflectie-op-actie & 6 & 6.0 & $3.6(.4)$ & .8 \\
Encapsulatie & 6 & 5.3 & $4.1(.4)$ & .8 \\
Vervolgen consult & 2 & 4.9 & $3.6(.7)$ & .7 \\
Reflectie-in-actie & 2 & 3.8 & $3.6(.9)$ & .7 \\
Gebruik patiënt & 2 & 3.3 & $3.6(.4)$ & .4 \\
Zelfsturing & 3 & 3.1 & $4.2(.3)$ & .5 \\
\hline
\end{tabular}

van de patiënt als leermiddel, en zelfsturing. Deze zeven factoren (dimensies) hadden een Eigenwaarde groter dan 1; hiermee werd $55 \%$ van de variantie verklaard (tabel 1). Zeven items pasten niet binnen de dimensies. Deze items zijn verder ook niet meegenomen in de analyses. Het aantal items per dimensie varieerde van twee tot zeven. De gemiddelde scores (vijfpuntsschaal) per dimensie varieerden van 3.6 tot 4.2 , de standaarddeviaties hierbij varieerden van .3 tot $.9(n=51)($ tabel 1$)$. De interne consistentie is voor vijf van de zeven dimensies groter dan .7 en voor de twee overige dimensies .4 en .5 (tabel 1).

Bij de vergelijking tussen de drie groepen begeleiders (relatief goed, gemiddeld, matig functionerend) werden significante verschillen $(\mathrm{p}<.05)$ gevonden bij de volgende dimensies: elaboratie, reflectie-op-actie, encapsulatie, gebruik van de patiënt als leermiddel en zelfsturing (figuur 2). De relatief goed functionerende begeleiders hebben op bijna alle dimensies de hoogste scores ontvangen. Zij scoren het hoogst op de dimensies elaboratie, encapsulatie en zelfsturing. De verschillen tussen de relatief goed functionerende begeleiders en de relatief matig functionerende begeleiders zijn het grootst op de dimensies elaboratie, reflectie-op-actie en encapsulatie. Op itemniveau scoren de relatief goed functione- rende begeleiders het hoogst $(\mathrm{p}<.05)$ op de volgende items:

- Vormt een goede voorbeeldfunctie als arts (omgang met de patiënt e.d.) (Zelfsturing).

- Vraagt naar nog niet aan bod gekomen aspecten (Elaboratie).

- Geeft informatie die aansluit bij de vraag van de studenten (Encapsulatie).

- Stimuleert het leggen van relaties tussen pathofysiologie en de verschillende klachten van de patiënt (Encapsulatie).

Alle hoog scorende items behoren tot de dimensies encapsulatie, elaboratie en zelfsturing.

In figuur 3 is het functioneren van de begeleiders van de verschillende capaciteitsgroepen weergegeven. Significante verschillen $(\mathrm{p}<.05)$ werden gevonden bij de dimensies elaboratie, vervolgen van het consult, reflectie-in-actie en gebruik van de patiënt als leermiddel. Op drie van deze vier dimensies scoren de internisten het hoogst. Zij stimuleren met name elaboratie, encapsulatie en zelfsturing. Op één dimensie (vervolgen van het consult) scoren de chirurgen significant hoger dan de internisten en de neurologen.

\section{Discussie en conclusie}

Deze studie heeft uiteraard tekortkomingen. Een belangrijke beperking is dat als onderzoekmethode een vragenlijst is ge- 
Figuur 2. Functioneren van drie groepen begeleiders op de zeven dimensies.

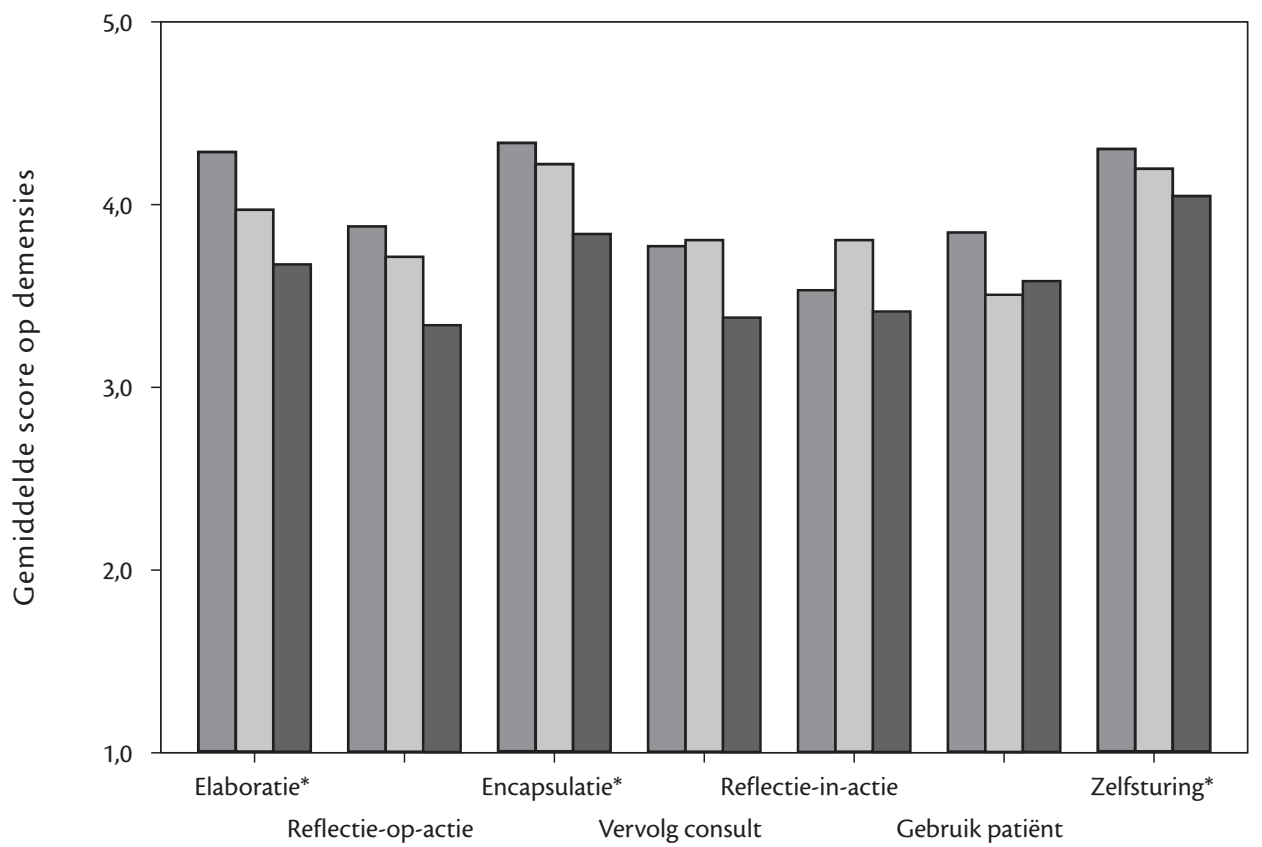

Dimensies

Relatief goed functionerende begeleiders $(n=17)$

Relatief gemiddeld functionerende begeleiders $(n=17)$

Relatief matig functionerende begeleiders $(n=17)$

$=p<.05$

bruikt die uitgaat van percepties van studenten. Een nadeel hiervan is dat het gedrag van de begeleiders niet direct gemeten wordt. Om het gedrag direct te meten, moeten andere onderzoeksmethoden gebruikt worden, bijvoorbeeld observaties en video-opnames.

Het doel van de studie was om te bepalen of de ontwikkelde vragenlijst om het gedrag van KOW-begeleiders te beoordelen intern consistent en valide is en of er verschillen zijn tussen begeleiders van de KOW. De factoren die uit de exploratieve factoranalyse naar voren zijn gekomen, komen overeen met de doelstellingen van de KOW en het theoretische kader van waaruit de vragenlijst is ontwikkeld. Hierbij moet opgemerkt worden dat er discussie mogelijk is over theoretische uitgangspunten met betrekking tot het verwerven van kennis en klinisch redeneren. 1314

Voor vijf van de zeven dimensies bleek de vragenlijst intern consistent te zijn. Voor twee van de zeven dimensies is de interne consistentie laag (.4 en .5), aangezien deze dimensies maar uit twee en drie items bestaan. De gebruikte vragenlijst zal in de toekomst op dit punt veranderd worden.

Uit de programma-evaluatie blijkt dat het gemiddelde oordeel van de studenten over het functioneren van de begeleiders net als in voorgaande jaren vrij hoog ligt: $7.7(\mathrm{sd}=.6, \mathrm{n}=51)$. De resultaten laten zien dat er voor een aantal factoren duidelijke 
Figuur 3. Functioneren van begeleiders van de drie capaciteitsgroepen op de zeven dimensies.

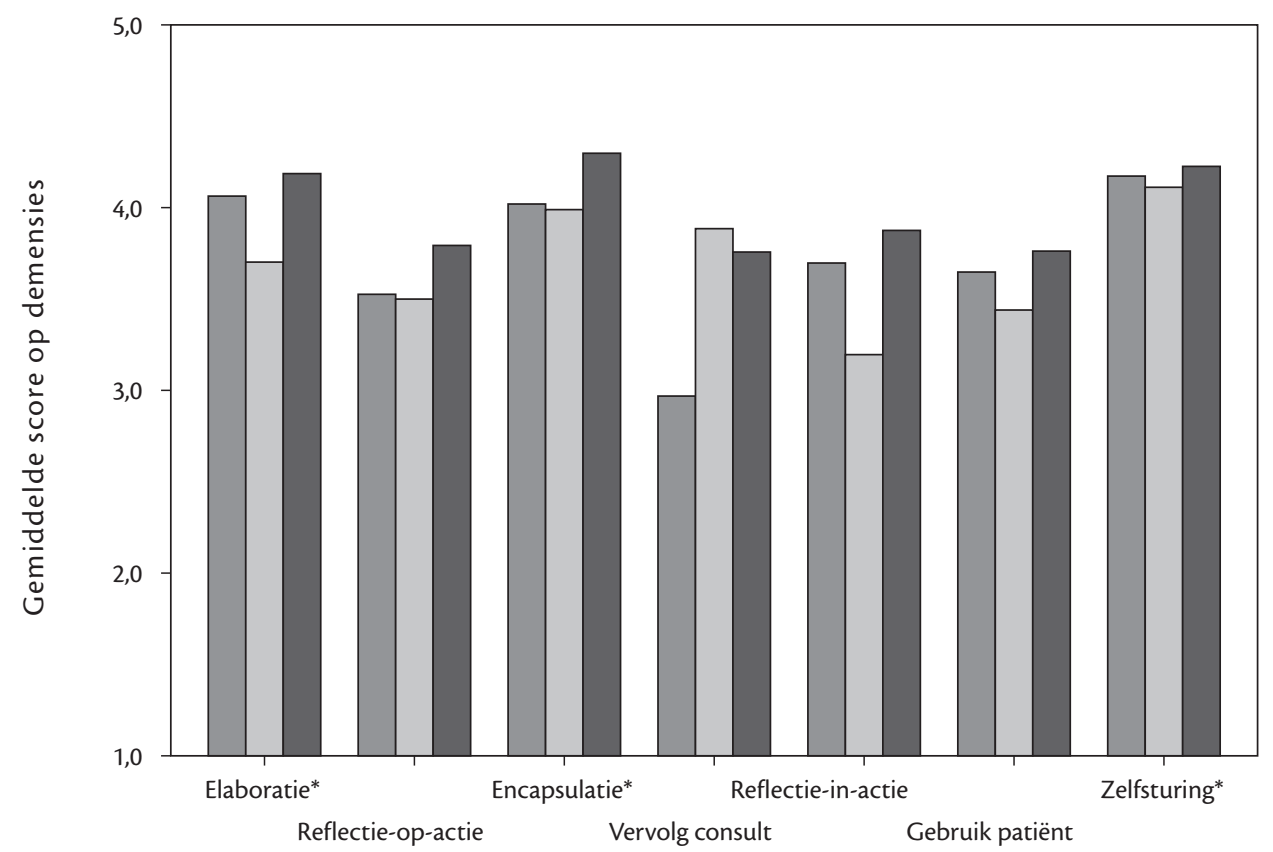

Dimensies

Neurologie begeleiders $(n=11)$

Chirurgie begeleiders $(n=20)$

Interne geneeskunde begeleiders $(n=20)$

$=p<.05$

verschillen zijn tussen begeleiders. Zowel op dimensie- als op itemniveau zijn er significante verschillen. De relatief goede begeleiders scoren het hoogst op de dimensies elaboratie en encapsulatie. Deze dimensies vormen een belangrijke indicatie voor de beoordeling door de studenten van de kwaliteit van de begeleider. De relatief goede begeleiders scoren ook hoog op de dimensie zelfsturing, maar deze factor blijkt niet intern consistent te zijn. De twee dimensies elaboratie en encapsulatie komen overeen met de doelstelling van de KOW: studenten aan de hand van concrete praktijksituaties stimuleren in het proces van integratie van biomedische en klinische kennis.
De relatief matig functionerende begeleiders zouden zich vooral moeten verbeteren binnen de dimensies elaboratie, reflectie-op-actie en encapsulatie. Binnen deze dimensies zijn de verschillen tussen de relatief goed en relatief matig functionerende begeleiders namelijk het grootst. De resultaten bevestigen het belang van het stimuleren van het leerproces door een begeleider. Begeleiders die met name aandacht besteden aan elaboratie en encapsulatie krijgen een betere beoordeling van de studenten.

Een mogelijke verklaring voor de gevonden verschillen tussen de begeleiders is dat zij verschillende ideeën over leren en onderwijzen kunnen hebben. Misschien 
hebben sommige begeleiders naïeve opvattingen of beperkte kennis over effectief leren, die het gedrag van de begeleiders kunnen beïnvloeden. ${ }^{15}$

Ook tussen de begeleiders van de drie capaciteitsgroepen zijn er verschillen zichtbaar. Interne geneeskunde scoort gemiddeld genomen het hoogst. Mogelijk wordt dit verklaard door de verschillen in vooropleiding en klinische werkzaamheden. Het accent van de KOW-bijeenkomsten ligt op klinisch redeneren. Waarschijnlijk hebben de internisten door hun dagelijkse werkzaamheden meer ervaring met het analyseren van dit onderdeel van het diagnostisch proces. Nader onderzoek zal moeten worden uitgevoerd om hier duidelijkheid over te verschaffen.

In nieuwe curricula die op dit moment worden ontwikkeld, wordt veel aandacht besteed aan een vroege integratie van theorie en praktijk. ${ }^{16} 17$ Bijeenkomsten die te vergelijken zijn met de huidige KOW-bijeenkomsten, zullen dan ook eerder in het curriculum gaan plaatsvinden. Dit heeft consequenties voor de rol van klinische begeleiders. Er zullen andere eisen aan hen worden gesteld. Voor deze nieuwe rol zullen de begeleiders moeten worden getraind. Dit onderzoek levert aanwijzingen waarmee materiaal ontwikkeld kan worden om klinische begeleiders te trainen, waarbij het leren stimuleren van met name elaboratie en encapsulatie voldoende aan bod moet komen. De vragenlijst kan tevens gebruikt worden als feedbackinstrument voor de begeleiders van de KOW, op basis waarvan zij hun gedrag kunnen verbeteren.

\section{Literatuur}

1. Wiel MWJ van de. Knowledge encapsulation [proefschrift]. Wageningen: Pons \& Looijen; 1997.

2. Wiel MWJ van de, Schaper NC, Scherpbier AJJA, Vleuten CPM van der, Boshuizen HPA. Students' experiences with real-patient tutorials in a problem-based curriculum. Teaching and Learning in Medicine 1999;11:12-20.
3. Bordage G. Elaborated knowledge: A key to successful diagnostic thinking. Acad Med 1994;69:883-5.

4. Boshuizen HPA, Schmidt HG. The development of clinical reasoning expertise. In: Higgs J, Jones M. eds. Clinical reasoning in the health professions. Butterworth-Heinemann; 2000. p. 15-23.

5. Grave WS de. Probleemgestuurd leren als kennisconstructie [proefschrift]. Maastricht: Datawyse; 1998.

6. Edwards JC, Marier RL, Bing-You RG. Clinical teaching techniques for residents. In: Edwards JC, Friedland JA, Bing You RG. eds. Residents' teaching skills: New York, NY: Springer Publishing Company, Inc; 2002. p. 38-65.

7. Schmidt HG, Boshuizen HPA. Encapsulation of biomedical knowledge. In: Evans AE, Patel VL. eds. Advanced models of cognition for medical training and practice. New York, NY: Springer Verlag; 1992. p. 265-82.

8. Charlin B, Tardif J, Boshuizen HPA. Scripts and medical diagnostic knowledge: theory and applications for clinical reasoning instruction and research. Acad Med 2000;75:182-90.

9. Parsell G, Bligh J. Recent perspectives on clinical teaching. Med Educ 2001;35:409-14.

10. Korthagen FAJ. Reflectie en de professionele ontwikkeling van leraren. Pedagogische Studiën 1992;69:112-23.

11. Cox K. Planning bedside teaching - 6. Reflection on the clinical experience. The Medical Journal of Australia 1993;158:607-8.

12. Spencer J, Blackmore D, Heard S, McCrorie P, McHaffie D, Scherpbier AJJA, et al. Patient-oriented learning: a review of the role of the patient in the education of medical students.

13. Colliver JA. Effectiveness of problem-based learning curricula: research and theory. Acad Med 2000;75:259-66.

14. Norman G. Holding on to the philosophy and keeping the faith. Med Educ 2001;35:820-1.

15. Entwistle N, Skinner D, Entwistle D, Orr S. Conceptions and beliefs about "good teaching": an integration of contrasting research areas. Higher Education \& Development 2000;19:5-26.

16. Scherpbier AJJA, Crebolder HFJM, Daemen MJAP, Damen JL, Dunselman GAJ, Farla PB, et al. Voorstel voor het nieuwe Maastrichtse curriculum. Maastricht: Onderwijsinstituut Faculteit der Geneeskunde; 2000.

17. Borleffs JCC, Mulder H, Smal JA. CRU'99: uitgangspunten en karakteristieken. Tijdschrift voor Medisch Onderwijs 2001;20(Supplement):S7-S10.

De auteurs:

Drs. I. Oosterhof is student geneeskunde en als studentassistent verbonden aan de Capaciteitsgroep Onderwijsontwikkeling en Onderwijsresearch, Faculteit der Geneeskunde, Universiteit Maastricht. 
Dr. W.S. de Grave en dr. D.H.J.M. Dolmans zijn als onderwijskundigen verbonden aan de Capaciteitsgroep Onderwijsontwikkeling en Onderwijsresearch, Faculteit der Geneeskunde, Universiteit Maastricht.

Dr. N.C. Schaper is als internist verbonden aan het Academisch Ziekenhuis Maastricht.

Prof. dr. C.P.M. van der Vleuten is voorzitter van de Capaciteitsgroep Onderwijsontwikkeling en Onderwijsresearch, Universiteit Maastricht.

\author{
Correspondentieadres: \\ W. de Grave, Capaciteitsgroep Onderwijsontwikkeling \\ en -research, Universiteit Maastricht, Postbus 616, \\ 6200 MD Maastricht. Tel: 043-3881117, i.oosterhof@ \\ student.unimaas.nl /w.degrave@educ.unimaas.nl.
}

\section{Summary}

Introduction: Fourth-year students at Maastricht medical school take part in seven real-patient tutorials (RPT). The main goal of the tutorials is integration of biomedical and clinical knowledge and hypothesis-based history taking. During the first 45 minutes of the RPT students take a history of a patient and the next 45 minutes are used for discussion of the history. The RPT is supervised by a clinician who knows the patient's problem. In this study a questionnaire was developed to measure the characteristics of the RPT supervisors.

Method: A questionnaire was developed consisting of 35 items about the characteristics of the supervisor (5-point Likert scale). In the academic year 2000-2001 190 students rated 51 supervisors by completing 1150 questionnaires directly after an RPT. A factor analysis and a reliability analysis were performed. One-way Anova was used to examine differences between the supervisors.

Results: The factor analysis revealed seven dimensions: elaboration, reflection-on-action, encapsulation, consult completing, reflection-in-action, the use of the patient as a learning tool, and self-direction. The internal consistency was generally high. Significant differences were found between the supervisors on several dimensions.

Conclusion: The questionnaire proved to be internally consistent and valid. The supervisors who received the highest scores from the students are characterized by high scores on the dimensions elaboration and encapsulation. The results of this study may be helpful in the training of supervisors and in providing them with feedback. (Oosterhof I, Grave WS de, Dolmans DHJM, Schaper NC, Vleuten CPM van der. The development of an instrument for measuring the functioning of supervisors of real patient tutorials. Dutch Journal of Medical Education 2002;21(3): 122-130.) 